\title{
A comparative study on investment casting of dental crowns for veterinary dentistry by using ABS patterns with and without wax coating
}

\author{
Smruti Ranjan Pradhan ${ }^{1 *}$, Rupinder Singh ${ }^{1}$, Sukhwant Singh Banwait ${ }^{1}$, Mukesh Singh Puhal ${ }^{1}$, Satinder Singh $^{1}$, and Arun \\ Anand $^{2}$, \\ ${ }^{1}$ NITTTR, Mechanical Engineering Department, Chandigarh 160019, India \\ ${ }^{2}$ GADVASU, Surgery and Radiology Department, Ludhiana 141004, Punjab, India
}

\begin{abstract}
The fused deposition modelling (FDM) assisted investment casting (IC) is one of the commercially established routes for fabrication of biomedical parts requiring high precision. In past two decades number of studies has been reported on use of thermoplastic and wax based FDM patterns for IC of dental crown (DC) in human dentistry. But hitherto little has been reported on comparison of Ni-Co-Cr based DC prepared by using FDM printed virgin acrylonitrile butadiene styrene (ABS) pattern and wax coated ABS pattern for veterinary patients (VP). In this work, first molar and canine teeth in left side of lower mandible of a 3-year German Shepherd male dog has been prepared by using virgin ABS and wax coated ABS patterns followed by IC of Ni-Co-Cr alloy. The result of study suggests that wax coated ABS samples-based DC has better surface hardness, grain structure, surface roughness (Ra) and controlled surface porosity thus may be used as commercial manufacturing strategy. The results have been supported with scanning electron microscopy (SEM) and energy dispersive X-ray (EDX) analysis.
\end{abstract}

\section{Introduction}

The fabrication of orthoses and prostheses as per the customized requirements includes selection of bio material, patient specific design and blended manufacturing processes for meeting the biomedical industry standards. Different orthoses are used for spine, knee, arm, hand/ wrist, hips, ankle, dental, cervical thoracic, diabetic shoe etc. for assisting externally and prostheses such as artificial teeth, limb, joint, artery, bone, heart valve and many other as per patient's requirement for their better life [1]. Commercially different conventional and non-conventional manufacturing techniques combined with digital modelling-based 3D printing (3DP) are being used for solving patient specific issues related to orthoses and prostheses. In case of VP, teeth are used for chewing foods, sensing and to defend themselves from any external attacks. During the life span of VP, teeth may be damaged due to any disease, traumatic condition, improper ingesting of food, fighting among them and natural wear and tear. So, these VP may require proper dental hygiene [2]. Non-conventional crown designing for VP is one of the troublesome techniques as the VP can't communicate directly. So, the combined decision of veterinarian, dentistry, VP owner play a significant role to address this issue. The dog is having eight strategic teeth. These are two canine teeth and two first

\footnotetext{
* Corresponding author: smrutijana@gmail.com
}

molar (M1) teeth in mandible and two canine teeth and two fourth premolar teeth in maxilla [3].

Different manufacturing processes such as computer aided design (CAD) based milling, electroforming, swaging, IC, 3DP etc. are used in fabrication of DC by using bulk of solid, liquid, wire and powder as material for humans as well as VP [4]. FDM is one of the thermoplastic filament wire fusion techniques used to fabricate simple to complex parts as per customised design requirements. In this process, a spool of wire fed to the extruder melted and passed precisely through the nozzle tip over the built platform to prepare the functional parts. The parameters like: nozzle tip diameter, wire thickness, wire melting temperature, layer height, infill geometry, air gap, density, staircase effect affects the final part properties [5]. So, the selection of parameters according to customized requirements plays an important role while designing and fabricating. The ABS is one of the biocompatible materials widely used as feed stock filament in FDM printers [6]. Lost wax IC is one of the oldest methods used for making high precision complex parts. But now a days this concept is adopted for making customized parts by using thermosetting resins and thermoplastic polymers in addition to paraffin wax, hard wax, microcrystalline wax and filler with hybridisation of CAD techniques [7]. Different types of wax are mainly aliphatic compounds having straight chain carbon atoms, whereas the resins and fillers are aromatic 
compounds having ring structured carbon atoms. The structure and composition of these compound determine key qualities such as hardness, viscosity, melting point, rheological features, congealing point, rate of expansion, contraction and setting [8,9]. Based on application, wax can be termed as runner wax, pattern wax, reconstituted reclaim wax, water soluble wax and special wax (for minute repair and finishing). Industry standard wax has been tested through drop (melting) point, ash content, congealing point, viscosity and penetration. The wax while melting in furnace undergoes subsequent phases as solid-plasticsemiplastic-semisolid-semiliquid-liquid to create cavity for casting. But the thermoplastic pattern evaporates directly at elevated temperature. After selecting specific pattern, ingate and runner material for IC, the preparation of investment is a significant phase. In this phase the parameters like powder to water concentration, mixing time, pouring height, angle of pouring, air entrapment, viscosity etc. are predominant for making of strong investment. In next phase, time of baking is important. After this, the pouring of molten metal into the baked investment in a controlled way also results the success of IC $[10,11]$. The literature review reveals that in past two decades number of studies has been reported on use of thermoplastic and wax based FDM patterns for IC of DC in human dentistry. But hitherto little has been reported on comparison of $\mathrm{Ni}$ Co-Cr based DC prepared by using FDM printed virgin ABS pattern and wax coated ABS pattern for VP. In this work, first molar and canine teeth in left side of lower mandible of a 3-year German Shepherd male dog has been prepared by using virgin $\mathrm{ABS}$ and wax coated ABS patterns followed by IC of Ni-Co-Cr alloy.

\section{Methodology}

The methodology adopted for this work is shown in Fig.1.

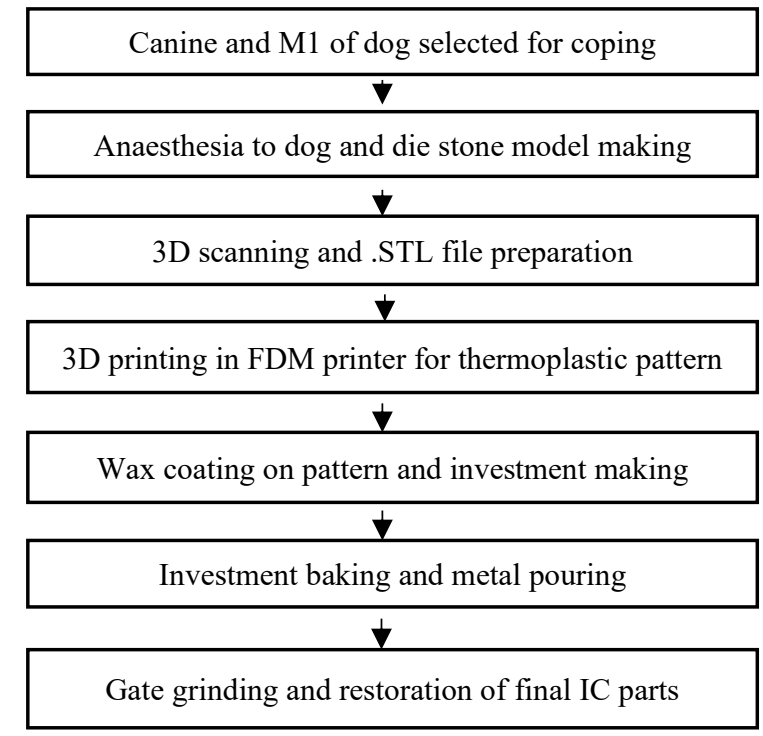

Fig. 1. Adopted path for 3D printing assisted metallic DC fabrication

\section{Experimentation}

\subsection{Development of die stone model}

In this step, initially a 3-year German Shepherd male dog was selected. The left mandibular canine and M1 tooth was fixed as bench mark. The dog was given anaesthesia for impression making. A stainless-steel dental tray with calcium alginate colloidal was placed inside the mouth of dog. The veterinary doctor force the lower left jaw against the dental tray to create tooth impression [12,13]. After this the tray was removed from the mouth of dog. The dental gypsum solution was poured into the selected tooth cavities of canine and M1. After hardening, the alginate portion was cut and die stone model was restored. The marking was done on the die stone model (tooth region selected for DC making) after cross verifying with the help of micro-meter and vernier calliper. The casted die stone model is shown in Fig. 2.
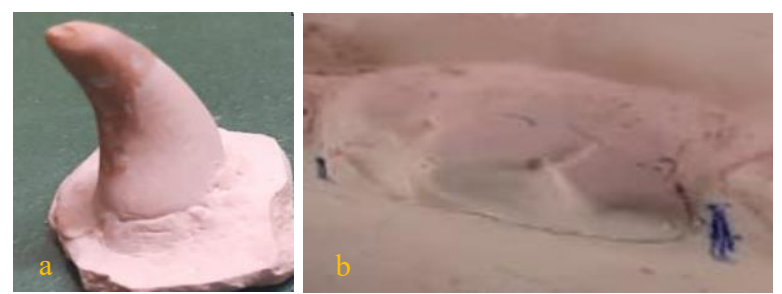

Fig. 2. Die stone models of left mandibular canine (a) and M1 (b)

\subsection{Virtual modelling for DC}

The die stone model of left mandibular canine and M1 teeth were scanned and surface data has been generated with the help of comet LED 5M 3D scanner [14]. The surface data was further processed for $3 \mathrm{D}$ modelling in 3-Shape dedicated dental software. In this dental software virtual DC in the form of .STL file was stored by providing $0.6 \mathrm{~mm}$ crown thickness. The virtual model of left mandibular canine and M1 are shown in Fig.3.
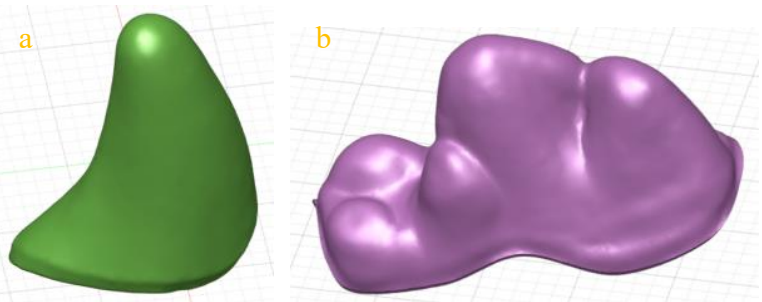

Fig. 3. Virtual model of left mandibular canine (a) and M1 (b)

\subsection{DP of selected DC}

The DC .STL files of left mandibular canine and M1 were imported into Catalyst EX dedicated software of uPrint FDM thermoplastic 3D printer. In this software, smart infill, sparse high density, ten number of copies, full scale with auto orientation were selected for printing. All the files were added into pack followed 
with printing command in software, where the number of layers, printing time, consumption of model material and support material were noted [15]. The start model command was pressed on the machine. The chamber was heated up to $78^{\circ} \mathrm{C}$ and material temperature was elevated to $300{ }^{\circ} \mathrm{C}$ which took around $12-15 \mathrm{~min}$. Here ABS was used as model material whereas polycarbonate (PC) used as soluble support material. After completion of printing, the parts were removed from the plastic platform and were put into the detergent solution for one day. The PC got dissolved in the detergent and the ABSbased actual thermoplastic DC was restored. The 3D printed thermoplastic DC were used as pattern material for IC. The thermoplastic DC fabricated by FDM printer is shown in Fig. 4.

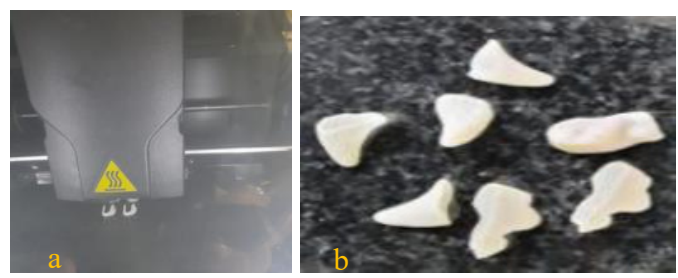

Fig. 4. Thermoplastic DC printing in FDM printer (a) and printed DC after cleaning (b)

\subsection{Metallic IC of DC}

The printed thermoplastic DC as pattern was divided into two groups for IC. Four patterns (two of each canine and M1) were kept as it was and six patterns (two of each canine and M1) were coated with wax externally for final investigation of surface characteristics [16]. Then sprue pattern was attached to each of pattern and put in a water bowl. The investment solution (IS) was prepared by mixing investment powder and required amount of water with the help of a spatula. Two investment trees (with and without wax coated) were made and placed inside the respective casting rings (CR). The prepared IS was poured into the two CR separately with a proper care to avoid bubble formation. The two CR were hardened within10-12 min. Then these CR were kept vertically downward inside the baking furnace for about $100 \mathrm{~min}$. The wax and ABS present inside CR were evaporated and cavity was created inside it. Then, two $\mathrm{CR}$ were removed from baking furnace. The Ni-Co-Cr base dental grade bullet were melted and poured into the first CR (without wax coated) which was attached to a centrifugal casing machine. After releasing spring load, the molten metal flew into the cavities of $\mathrm{CR}$ centrifugally. The solidification of molten metal took around $20 \mathrm{~min}$. The same molten metal pouring procedure was followed for the second CR (wax coated). Then the runner and sprue were machined and final metallic investment casted DC were restored. The IC process flow is shown in Fig. 5.
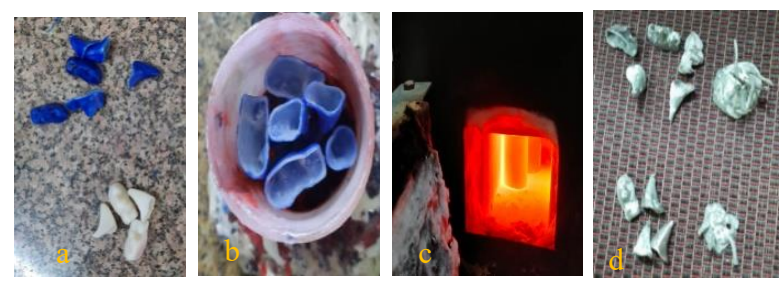

Fig. 5. ABS with and without wax coated thermoplastic DC (a), Patterns attached to sprue base well inside CR (b), CR placed inside baking furnace (c), Metallic DC after IC and gate grinding $(\mathrm{d})$

\section{Result Analysis}

The results were analysed for surface porosity based on ASTM B 276 standard; grain size analysis based on ASTM E 112 standard. The microhardness and electron dispersive X-ray (EDX) analysis was also carried out. The porosity, grain size, $\mathrm{Ra}$ and $3 \mathrm{D}$ rendered imagebased analysis is shown in Table 1-4. Based upon Table $1-4$, it has been ascertained that ABS+ wax based master pattern has less porosity (16.31\%) as compared to virgin ABS (23.41\%), small grain size number, less Ra value and better signature of amplitude distribution function. Hence ABS+ wax based master pattern may be considered as better option in comparison to virgin ABS.

Table 1. Porosity analysis of IC parts by using thermoplastic patterns with and without wax coating.

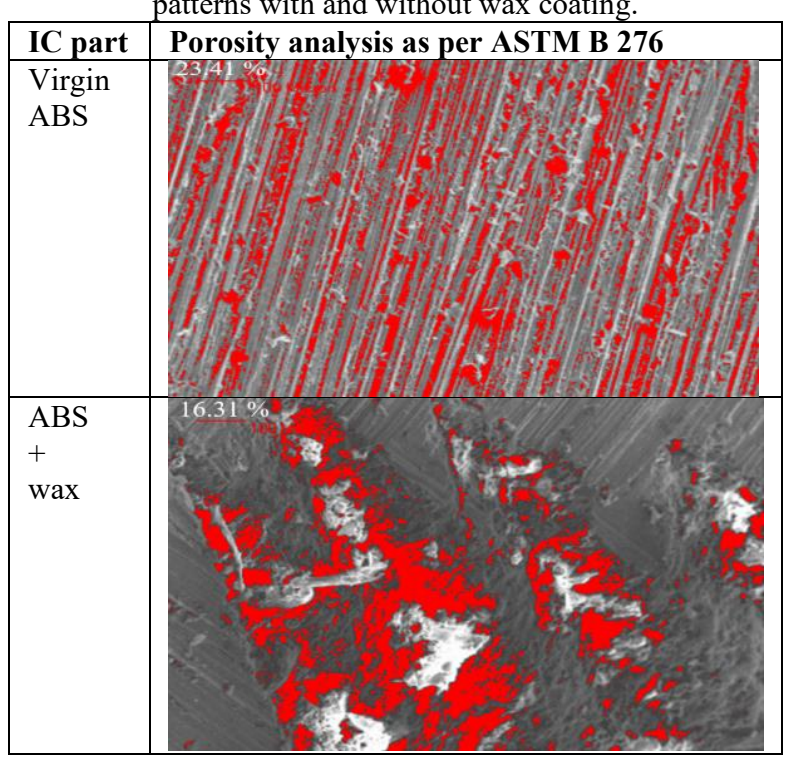

Table 2. Grain size analysis of IC parts using thermoplastic pattern with and without wax coating

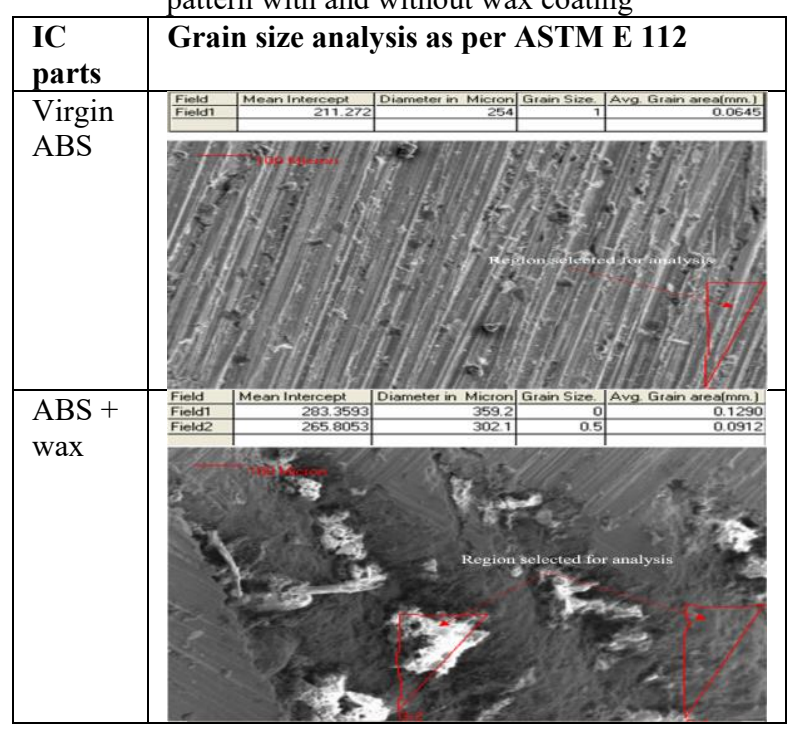

Table 3. Calculated relative $\mathrm{Ra}$ 


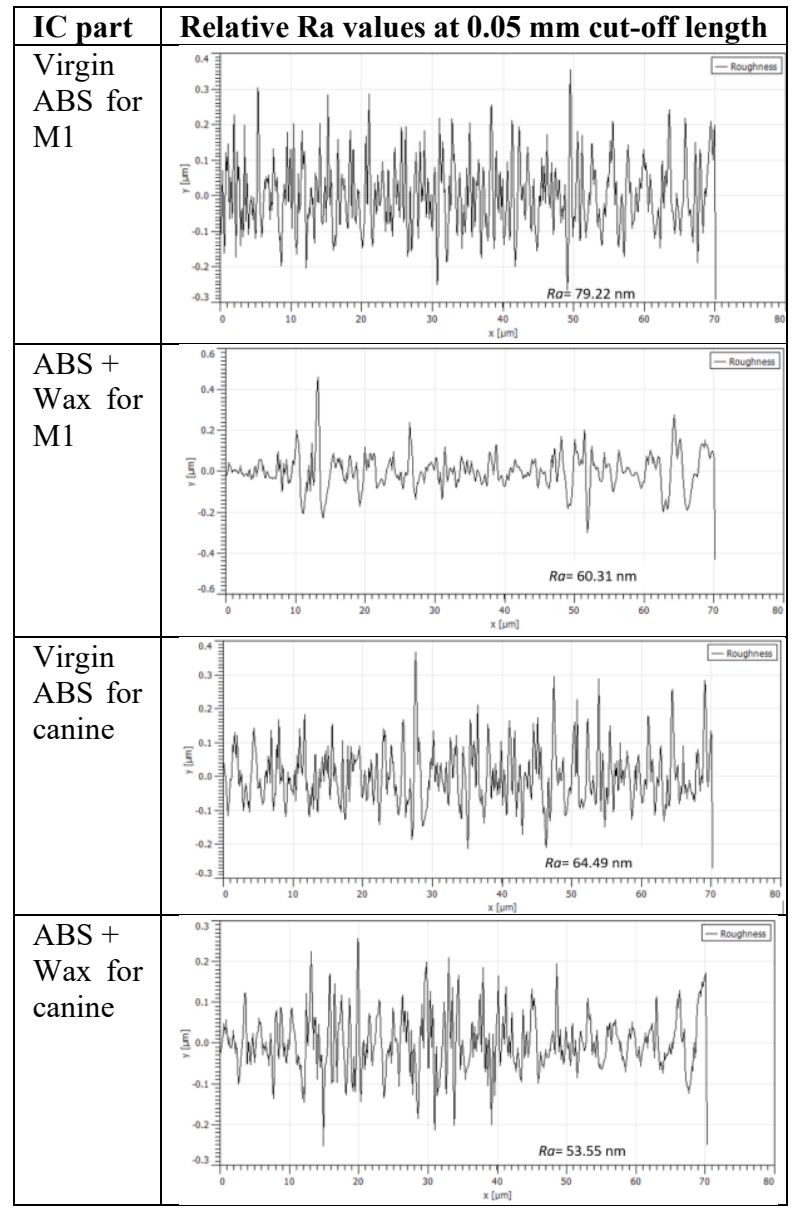

Table 4. 3D rendered SEM images and amplitude distribution function of metal casted DC

\begin{tabular}{|c|c|c|}
\hline IC part & $\begin{array}{l}\text { 3D rendered } \\
\text { SEM at } 100 \times\end{array}$ & $\begin{array}{l}\text { Amplitude distribution } \\
\text { function }\end{array}$ \\
\hline $\begin{array}{l}\text { Virgin } \\
\text { ABS for } \\
\text { M1 }\end{array}$ & & \\
\hline $\begin{array}{l}\mathrm{ABS}+ \\
\text { Wax for } \\
\text { M1 }\end{array}$ & & \\
\hline $\begin{array}{l}\text { Virgin } \\
\text { ABS for } \\
\text { canine }\end{array}$ & & \\
\hline $\begin{array}{l}\mathrm{ABS}+ \\
\text { Wax for } \\
\text { canine }\end{array}$ & & \\
\hline
\end{tabular}

\subsection{Mechanical (Microhardness) Test and EDX analysis}

The microhardness test was conducted at $0.2 \mathrm{~kg}$ load on each metallic DC produced by IC. The detail of test results is given in Table 5 .

Fig. 6-8 respectively shows EDX, area mapping, EDX spectrum and line mapping of $\mathrm{Ni}-\mathrm{Co}-\mathrm{Cr}$ alloy. The elemental analysis of $\mathrm{Ni}$ based dental alloy is shown in Table 6.

Table 5. Microhardness test results of different DC fabricated by IC.

\begin{tabular}{|l|l|l|}
\hline Microhardness tester & $\begin{array}{l}\text { IC } \\
\text { parts }\end{array}$ & $\begin{array}{l}\text { Values } \\
\text { in } \mathbf{H V} \text { at } \\
\mathbf{0 . 2} \mathbf{~ k g}\end{array}$ \\
\hline & $\begin{array}{l}\mathrm{ABS} \text { for } \\
\mathrm{M} 1\end{array}$ & 406.8 \\
\hline & $\begin{array}{l}\mathrm{ABS}+ \\
\text { Wax for } \\
\mathrm{M} 1\end{array}$ & 511.5 \\
\hline & $\begin{array}{l}\mathrm{ABS} \text { for } \\
\text { canine }\end{array}$ & 400.3 \\
\hline & $\begin{array}{l}\text { ABS }+ \\
\text { Wax for } \\
\text { canine }\end{array}$ & 503.1 \\
\hline
\end{tabular}

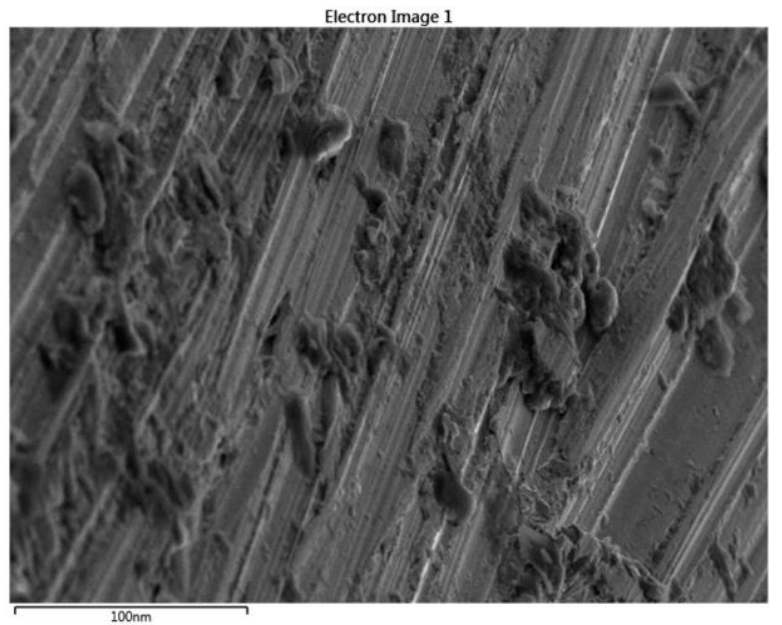

Fig. 6. EDX image at $400 \times$ of M1 metallic DC

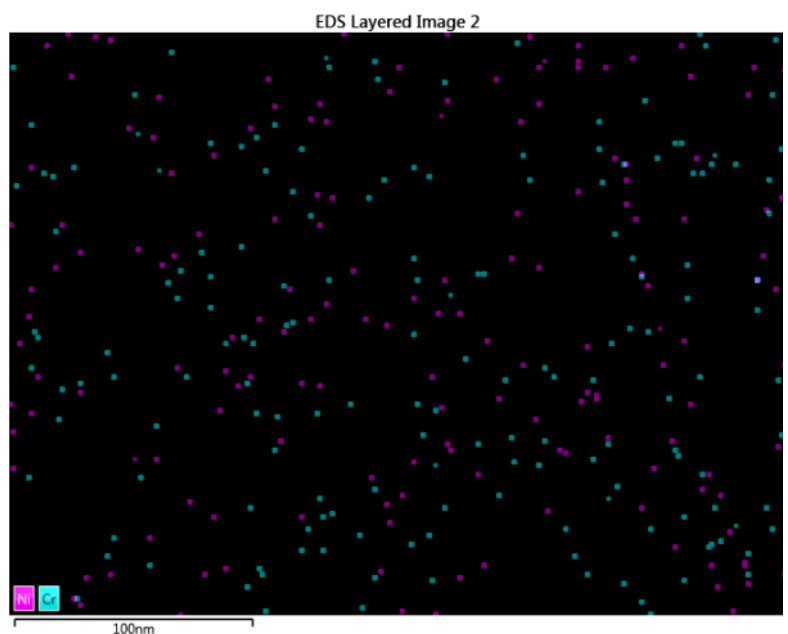

Fig.7. Area mapped EDX analysis between $\mathrm{Ni}$ and $\mathrm{Cr}$ 


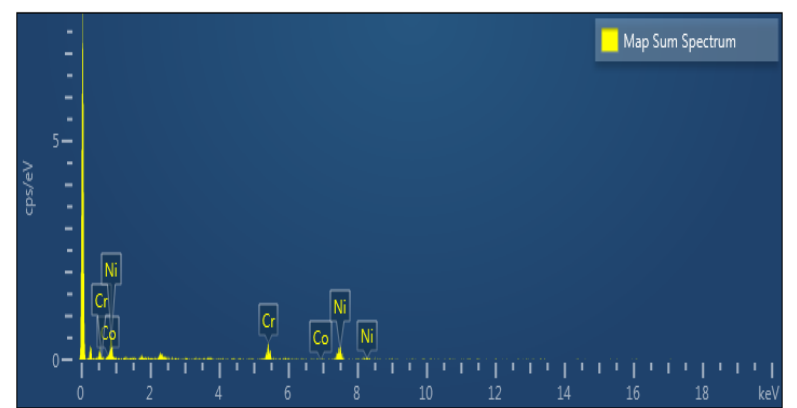

Fig.8. EDX spectrum shows different components of Ni base DC

Table 6. Elements with their percentage from EDX study

\begin{tabular}{|c|c|c|c|c|}
\hline $\begin{array}{l}\text { Map Sum } \\
\text { Spectrum }\end{array}$ & & & & \\
\hline Element & $\begin{array}{l}\text { Line } \\
\text { Type }\end{array}$ & $\begin{array}{c}\text { Weight } \\
\%\end{array}$ & $\begin{array}{c}\text { Weight } \\
\% \\
\text { Sigma }\end{array}$ & $\begin{array}{c}\text { Atomic } \\
\%\end{array}$ \\
\hline $\mathrm{Ni}$ & $\begin{array}{c}\mathrm{K} \\
\text { series }\end{array}$ & 56.61 & 4.47 & 57.44 \\
\hline $\mathrm{Cr}$ & $\begin{array}{c}\mathrm{K} \\
\text { series }\end{array}$ & 29.06 & 3.36 & 33.29 \\
\hline Mo & $\begin{array}{c}\mathrm{L} \\
\text { series }\end{array}$ & 13.38 & 4.49 & 8.31 \\
\hline $\mathrm{Co}$ & $\begin{array}{c}\mathrm{K} \\
\text { series }\end{array}$ & 0.95 & 1.64 & 0.96 \\
\hline Total & & 100.00 & & 100.00 \\
\hline
\end{tabular}

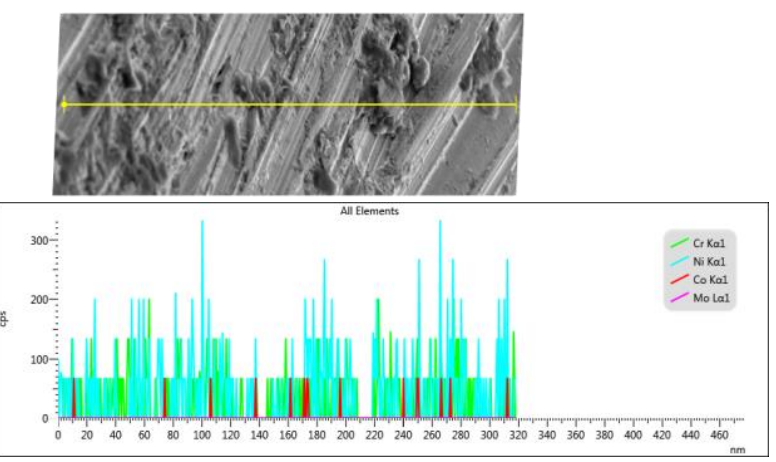

Fig. 9. Elemental line analysis on EDX image

\section{Conclusions}

Following are the conclusions from this work: -

- As regards to surface hardness is concerned the microhardness values has shown greater impact on metallic DC prepared by IC with wax coating on ABS pattern.

- The Ra of DC prepared by IC with wax coated pattern is better than that of virgin ABS pattern. Similar trend was observed for amplitude distribution function.

- The grain structure of DC prepared with ABS+ wax pattern is better than that of virgin ABS pattern.

- Due to wax coating over the ABS pattern, the porosity was also improved.

\section{Acknowledgements}

The author(s) are gratified to DST (GoI) for affording research amenities under FIST project (File No. SR/FST/COLLEGE/2020/997) and financial assistance by DBT (GoI) (File No.102/IFD/SAN/533/2017-18). Also special thanks to Precision Ceramic Artz, Mohali, Punjab (India), Panjab University, Chandigarh (India), Guru Angad Dev Veterinary and Animal Science University, Ludhiana, Punjab (India) and National Institute of Technical Teachers Training and Research, Chandigarh (India) for lab facilities.

\section{References}

1. N. Singh, R. Singh, IPS Ahuja, I. Farina, F. Fraternali, Composite Structures, 207, 129 (2019)

2. G. A. Zarb, A. Schmitt, Journal of oral rehabilitation, 22, 661 (1995).

3. K. Wingo, Journal of veterinary dentistry, 35, 4653 (2018)

4. S. Pradhan, R. Singh, S.S. Banwait, “A Frame Work on Crown Fabrication for Veterinary Patients Using 3D Thermoplastic and Metal Printing", in Reference Module in Materials Science and Materials Engineering, (2020).

5. M. Lemmons, D. Beebe, Oral anatomy and physiology. In Wiggs's Veterinary Dentistry: Principles and Practice, 1 (Wiley-Blackwell, 2019).

6. J. C. Wataha, The Journal of prosthetic dentistry, 83, 223 (2000).

7. M. Roach, Dental Clinics of North America, 51, 603 (2007).

8. G. Singh, R. Singh, S. Singh, Sadhana, 44, 1 (2019)

9. S. Pradhan, R. Singh, S.S. Banwait, S. Singh, A. Anand, "3D Printing assisted dental crowns for veterinary patients", in Reference Module in Materials Science and Materials Engineering, (Elsevier Inc ,2021)

10. R. Hirst, "Understanding investment casting wax" (Blayson Olefines, UK, 2010).

11. S. Logozzo, E. M. Zanetti, G. Franceschini, A. Kilpelä, A. Mäkynen, Optics and Lasers in Engineering, 54, 203 (2014).

12. S. Pradhan, R. Singh, S.S. Banwait, "On crown fabrication in prosthetic dentistry of veterinary patients: A review" in Advances in Materials and Processing Technologies., 1 (2021)

13. G. Singh, R. Singh, S. Singh, A. Bhardwaj, S. Singh, C. Prakash. "Comparison of $\mathrm{Ni}-\mathrm{Cr}$ based partial dentures prepared by thermoplastic and wax based investment casting: Mechanical, morphological and in-vitro analysis." In Materials Today: Proceedings (2021).

14. J.Riehl,J. W. Soukup,C. Collins, S. Siverling, H. L. Ploeg, C. J. Snyder, Journal of veterinary dentistry, 31, 22 (2014).

15. J. Singh, R. Singh, International Journal of Rapid Manufacturing, 1, 208 (2008) 
16. R. Singh, G. Singh, Transactions of the Indian Institute of Metals, 68, 17 (2015). 